\title{
Spatio-temporal change of grassland distribution in central Inner
}

\section{Mongolia in China}

\author{
Xia Meng ${ }^{1, a}$, Luo Guo ${ }^{2, b}$ \\ ${ }^{1,2}$ School of Life and Environmental Science, Minzu University of China, Beijing, China

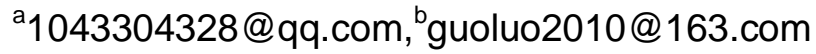

Keywords: grassland; Inner Mongolia; landscape pattern; spatio-temporal change

Abstract. Grassland is one of most important ecosystems in northern China and is threatened by strong land use pressure and poor protection. We selected central Inner Mongolia as a study area to explore spatio-temporal change of grassland distribution in the north of China. Obtaining land use data from remote sensing maps, we classified it into six types: forest, grassland, wetland, farmland, artificial surface and others. Then grassland was assigned into four secondary categories: meadow, steppe, tussock and herbaceous greenbelt. On the base of RS and GIS, we made an analysis of grassland distribution from 2000 to 2010. Result shows: 1) during this period, distribution of grassland decreased $1472.68 \mathrm{~km}^{2}$, accounting for $0.45 \%$; 2) steppes took up the biggest percentage of total area, which experienced lighter decline compared with herbaceous greenbelts; 3) differing from the total trend, tussock suffered little degradation while meadows expended to some degree.

\section{Introduction}

Grassland is one of the most extensive ecosystems in the world and plays a key role in ecosystem services, carbon balancing and climate regulation [1]. Over past decades, earth has undergone dramatic environmental changes and grassland displayed greater vulnerability than other ecosystems [2, 3]. In China, grassland is the most widespread land type occupying about $40 \%$ of nation's territorial area [4]. About 78\% of grasslands are located in the northern temperate arid and semi arid zones of China [5]. Grasslands are very important for local people, because they are the easiest among all vegetations to clean for cropping and most suitable for grazing [6,7]. However, since 1970s most of grasslands suffered heavily from harsh climate, population growth and extensive land use, resulting in a severe land degradation and productivity decline $[8,9,10]$. Understanding the change pattern of grassland is attached much weight.

Inner Mongolia, which takes up the biggest percentage of grassland in China, located in the Mongolian Plateau, consists of six plateaus from east to west: the Hulunbuir Plateau, the Xilingol Plateau, the Wulanchabu Plateau, the Ordos Plateau, the Bayannoir Plateau, and the Alashan Plateau[11]. Human land use in this region has experienced a series of transitions from primitive agriculture and fisheries in prehistoric periods to nomadism that lasted for a few 1000 years and to secondary nomadism with increasing agriculture and urbanization during the past decades [12,13]. However, in the past decades, grasslands in Inner Mongolia degraded to a certain degree due to human activity and climate change [14].Before we take measures to protect local grassland, having a good acknowledgement of how it varies is of importance. Our objective are to: 1) systematically classify grasslands into four types and help readers have a good knowledge of landscape pattern of grasslands, and 2) to provide the information on dynamic variations of Inner Mongolia's grasslands 
in the past decade and facilitate further study carried about degradation of grassland in the future.

\section{Study area}

Study area concludes the Xilingol Plateau and the Wulanchabu Plateau(Fig. 1) in the central Inner Mongolia where most of grasslands are located. Inner Mongolia is in the north of China, covering an area of 120 million ha and accounting for $12 \%$ of China's land area. Its climate is dominated by continental climate with mean annual temperature from -2 to $6{ }^{\circ} \mathrm{C}$ and mean annual precipitation varying from 40 to $450 \mathrm{~mm}$. Inner Mongolia has several types of zonal vegetation including temperate coniferous and deciduous forest, meadow steppe, typical steppe, desert steppe, steppe desert, desert because of varying precipitation. Grasslands of different kinds are the most dominant vegetation, occupying 78.8 million ha, about $67 \%$ of Inner Mongolia's territory [15].

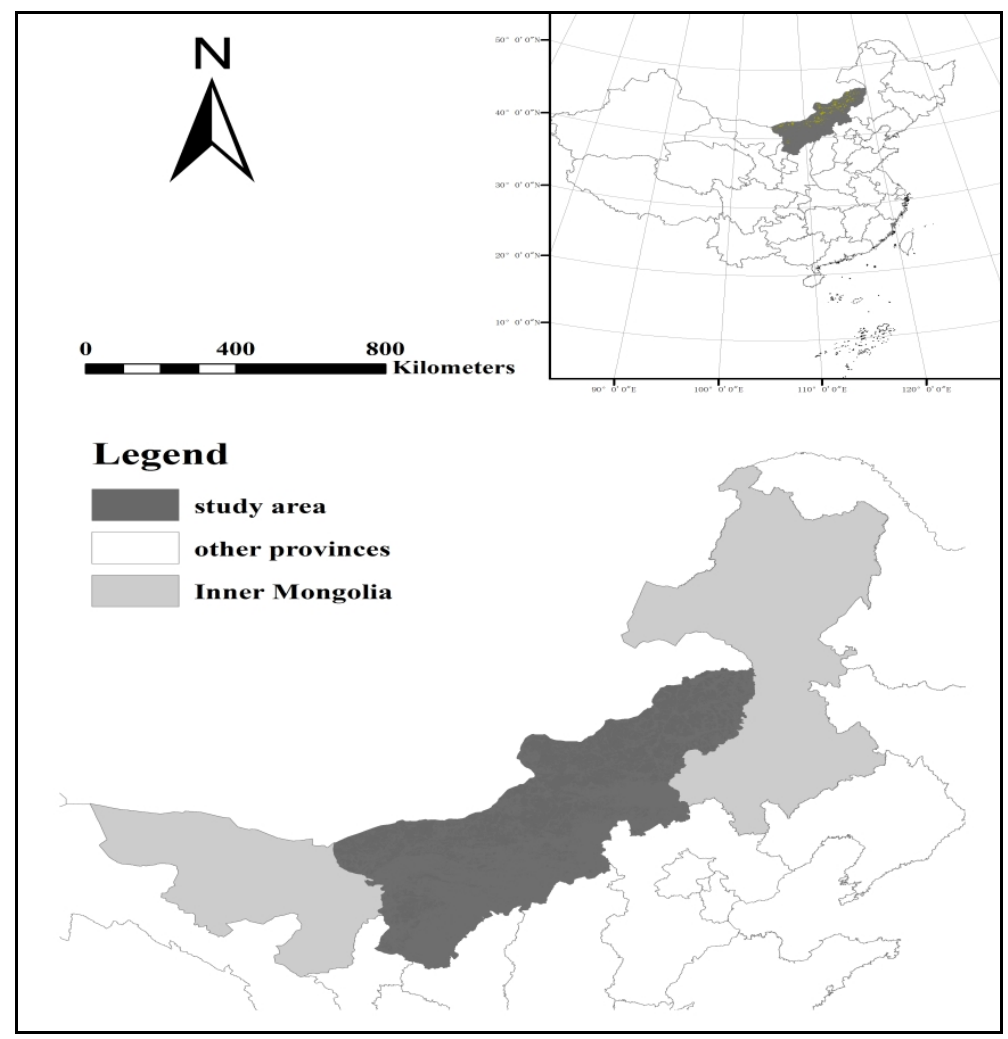

Fig.1, location of study area

\section{Method}

We used Landsat ETM remote sensing images in 2000 and remote sensing images in 2010 obtained from Satellite Environment Center for research. Land use/cover was classified into six primary types corresponding to the land use/cover types of Intergovernmental Panel on Climate Change (IPCC) including forest, grassland, wetland, farmland, artificial surface and others. Secondary land use/cover types were classified based on the Land Cover Classification System (LCCS) and grassland system consisted of meadow, steppe, tussock and herbaceous greenbelt. (Fig. 2). On the base of RS and GIS, we made an analysis of distribution of grasslands in Inner Mongolia from 2000 to 2010 . 


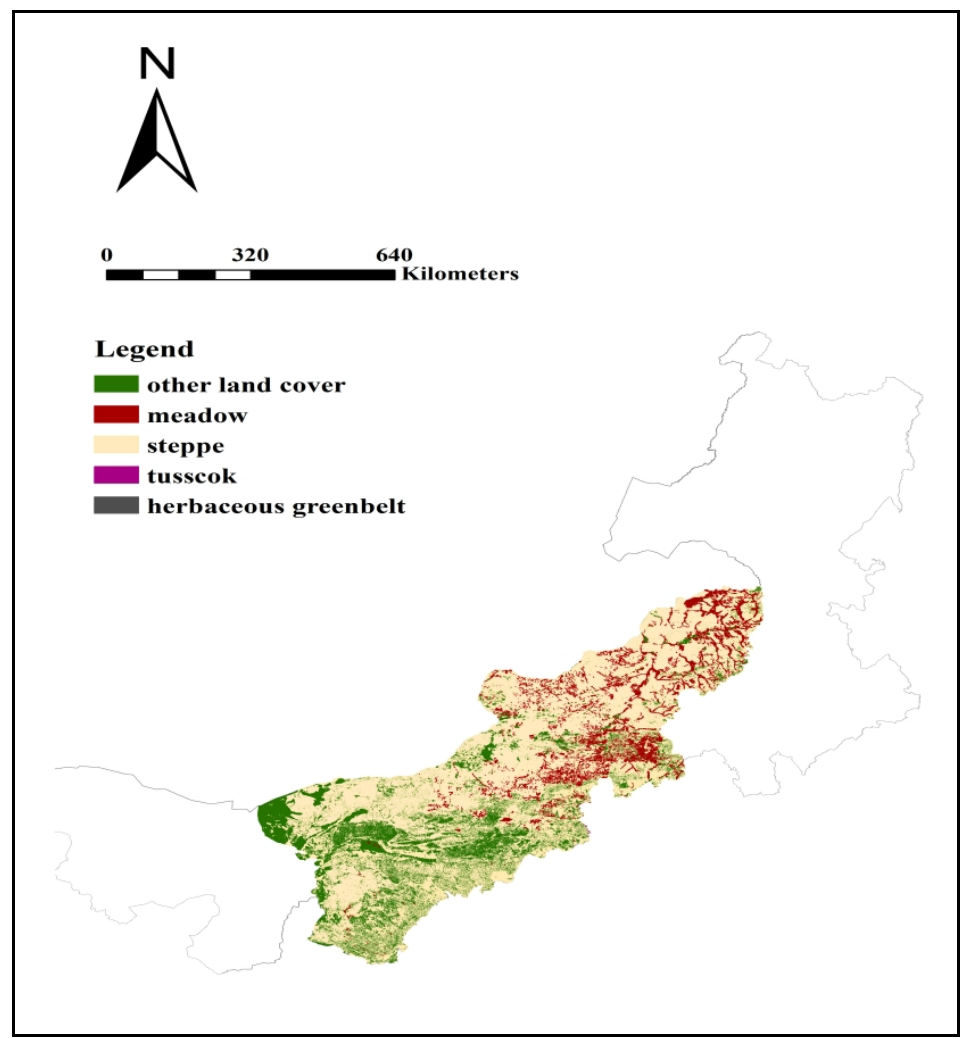

Fig.2, land cover of grassland in study area in 2010

\section{Results and conclusions}

Total trend of grassland Most of grasslands are located in the central area of Inner Mongolia and they are mainly decided by climate. During the past decade, climate factors were unevenly distributed in space and time. Precipitation decreased from southwest to northeast while temperature showed a contrary trend, which favored regional dominant plant community growth. From 2000 to 2010 , distribution of grassland had a decrease of $1472.67 \mathrm{~km}^{2}$ (Table 1), accounting for $0.45 \%$ of total area.

Waving in distribution of 4 grasslands Steppes take up the biggest percent of total area, which experienced smaller decline compared with herbaceous greenbelt, showing stronger reliance while herbaceous greenbelt suffered the most severe decline in the past decade. It can be assumed that dominant communities in herbaceous greenbelt are more easily to be affected by human activity and climate. Differing from the total trend, tussock suffered little degradation which is too small to calculate while meadows expended to some degree, which attributed to ecological restoration projects funded by government.

Table 1, Distribution of wetlands in 2000 and 2010 in Inner Mongolia

\begin{tabular}{lccc}
\hline Types & \multicolumn{2}{c}{ Area of distribution[ $\left.\mathrm{km}^{2}\right]$} \\
\cline { 2 - 4 } & 2000 & 2010 & $\begin{array}{c}\text { decline in the past } \\
\text { decade [\%] }\end{array}$ \\
\cline { 2 - 4 } Meadow & 12440.24 & 12468.90 & -0.23 \\
Steppe & 316187.20 & 314687.30 & 0.47 \\
Tussock & 4.38 & 4.38 & 0 \\
Herbaceous greenbelt & 15.73 & 14.30 & 9.09 \\
Total & 328647.55 & 327174.88 & 0.45 \\
\hline
\end{tabular}




\section{Acknowledgements}

The work presented in this paper was supported by the National Natural Science Foundation of China (31370480), 111Project(B08044)and Minzu University of China (MUC First-class Subjects foundation).

\section{References}

[1] Zhaoqi Wang, Yanzhen Zhang and Yue Yang: Ecological Informatics Forum Vol. 33 (2016), p. 32

[2] Haojie $\mathrm{Xu}$, Xinping Wang and Xiaoxiao Zhang: Ecological Engineering Forum Vol. 92 (2016), p. 251

[3] Weicheng Wu, Claudio Zucca and Fadi Karam: International Journal of Applied Earth Observation and Geoinformation Forum Vol. 52 (2016), p. 422

[4] Felipe Pereira Marinho, Guilherme Gerhardt Mazzochini and Adriana Pellegrini Manh aes: Journal of Arid Environments Forum Vol. 132 (2016), p. 26

[5] Xiaoying Gong, Marcus Giese : Geoderma Forum Vol. 282 (2016), p. 112

[6] Fabienne Trolard, Guilhem Bourrie and Antoine Baillieux: Journal of Environmental Management Forum Vol. 181 (2016), p. 590

[7] Ying Zhang, Chaobin Zhang, Zhaoqi Wang, Yizhao Chen: Science of the Total Environment Forum Vol. 83-87 (1992), p. 119

[8] Shuai Li, Wei Liang and Bojie Fu: Science of the Total Environment Forum Vol. 569-570 (1992), p. 119

[9] Qinpu Luo, Jirui Gong, Zhanwei Zhai, Yan Pan, Min Liu, Sha Xu, Yihui Wang: Science of the Total Environment Forum Vol. 569-570 (2016), p. 1466

[10] Aki Yanagawa, Takehiro Sasaki and Undarmaa Jamsran: Journal of Arid Environments Forum Vol. 131 (2016), p. 1

[11] Amy N. Birtwistle, Melinda Laituri and Brian Bledsoe: Journal of Arid Environments Forum Vol. 131 (2016), p. 15

[12]Qian Zhang, Wenjun Li: Journal of Arid Land Resource and Environment Forum Vol. 22 (2008), p. 8 (in Chinese)

[13]Zhongling Liu, Wei Wang and Dunyuan Hao: Journal of Arid Land Resource and Environment Forum Vol. 16 (2002), p. 84 (in Chinese)

[14]Ruifang Ma, Maosong Li and Xiuzhi Ma: Inner Mongolian Meterology Forum Vol. 2 (2011), p. 30

[15]Jianguo Wu, Qing Zhang, AngLi and Cunzhu Liang: Landscape Ecology Forum Vol. 30 (2015), p. 1579 